\title{
Hemodynamic Changes in HH Stage 34 Chick Embryos after Treatment with All-trans-Retinoic Acid
}

\author{
MONIQUE L. A. BROEKHUIZEN, HANNIE G. A. BOUMAN, FRANS MAST, PAUL G. H. MULDER, \\ ADRIANA C. GITTENBERGER-DE GROOT, AND JURIY W. WLADIMIROFF \\ Department of Obstetrics and Gynecology [M.L.A.B., J.W.W.] and Department of Epidemiology and \\ Biostatistics [P.G.H.M.], Academic Hospital Dijkzigt, Erasmus University, Rotterdam; Department of \\ Anatomy and Embryology [H.G.A.B., A.C.G.-d.G.], University of Leiden; and Department of Physiology, \\ CARIM [F.M.], Maastricht, The Netherlands
}

\begin{abstract}
To obtain insight into the hemodynamics of abnormal cardiac development, a chick embryo model was recently developed in which a spectrum of double outlet right ventricle was induced with all-trans-retinoic acid. In Hamburger and Hamilton $(\mathrm{HH})$ stage 34 white Leghorn chick embryos, we simultaneously measured dorsal aortic flow velocities with a $20 \mathrm{MHz}$ pulsed Doppler velocity meter and vitelline artery blood pressures with a servonull system. These measurements were performed in embryos treated at HH stage 15 with $1 \mu \mathrm{g}$ of all-trans-retinoic acid $(n=$ $47)$, or with the solvent DMSO $(n=15)$, and in control embryos $(n=21)$. After the wave form recordings were collected, all embryos were examined histologically. Embryos treated with all-trans-retinoic acid showed in 15 cases hearts with a rightward positioned aorta with an additional subaortic ventricular septal defect and 32 cases without septation abnormalities of the heart. The hemodynamic data were correlated with the morphology.
\end{abstract}

ABSTRACT
Cardiac development is a dynamic process involving complex structural changes accompanied by dramatic changes in hemodynamic function. Hemodynamics is concerned with the forces generated by the heart and the resulting motion of blood through the cardiovascular system. The multifaceted process of the interrelationship between form and function is a therefore major challenge to developmental biologists. Micro-Doppler and pressure studies in chick embryos have provided valuable information on this relationship in normal heart development $(1,2)$. To obtain insight into the hemodynamics in abnormal cardiac development, a chick embryo model was recently developed in which cardiac malformations as part of a continuous

Received July 14, 1994; accepted March 9, 1995.

Correspondence and reprint requests: J. W. Wladimiroff, M.D., Ph.D., Department of Obstetrics and Gynccology, Academic Hospital Dijkzigt, Erasmus University Roltcrdam, Dr. Molewaterplein 40, 3015 GD Rolterdam, The Netherlands.

Supported by a grant of the Netherlands Heart Foundation and the Netherlands Organization for Scientific Research Grant 900-516-096.
Statistical comparison was performed between control and experimental values. There was no significant discrepancy in hemodynamics of sham-operated and control embryos. Heart rate, peak systolic and mean velocities, peak systolic and mean blood flows, and peak acceleration and stroke volume were reduced in embryos treated with all-trans-retinoic acid $(p<0.01)$. Furthermore, in the presence of a subaortic ventricular septal defect the diameter of the dorsal aorta was reduced. Pressure readings were not statistically significant. Our findings suggest that the hemodynamic changes are the result of a decrease in cardiac contraction force. (Pediatr Res 38: 342-348, 1995)

\section{Abbreviations}

HH stage, Hamburger and Hamilton stage $\mathbf{d P} / \mathbf{d t}$, change in pressure per unit time $\mathbf{d V} / \mathbf{d t}$, peak acceleration spectrum were induced with all-trans-retinoic acid, a cardiac teratogen $(3,4)$. The heart malformations showed a spectrum of a rightward shift of the aorta. The rightward positioned aorta was still connected to the left ventricle in cases without a ventricular septal defect and were classified as having no septation abnormalities. In the presence of a ventricular septal defect, in combination with the rightward positioned aorta, this anomaly was diagnosed as double outlet right ventricle (5). This model will allow us to evaluate the cellular biologic aspects of the influence of all-trans-retinoic acid on cardiac morphogenesis as well as the assessment of the hemodynamic parameters involved.

The objective of the present study was to establish whether a difference in hemodynamics existed between embryos with a normally developing heart and embryos with a developing double outlet right ventricle after all-trans-retinoic acid treatment. HH stage 34 was selected because the cardiac defect was easy to diagnose in this stage (5). 


\section{METHODS}

Fertilized White Leghorn chick eggs were incubated (blunt end up) at $38^{\circ} \mathrm{C}$ and staged according to Hamburger and Hamilton (6). The material was subdivided into groups of embryos treated with a solution of all-trans-retinoic acid and the solvent DMSO, embryos treated with only the solvent (sham-operated embryos) and control embryos.

At $\mathrm{HH}$ stage 15 (d 21/2 of a 21 -d incubation) each embryo, with exception of the controls, was exposed by creating a window in the shell followed by removal of the overlying membranes. Either a solution containing $1.0 \mu \mathrm{g}$ of all-transretinoic acid or only the solvent $2 \%$ DMSO was then deposited on the vitelline membrane of the embryo using a Hamilton syringe (5). After administration of the solution, the window was sealed with tape and the egg reincubated.

Physiologic measurements were performed at HH stage 34 ( $\mathrm{d} 8$ of incubation) because the cardiac defect could be diagnosed with certainty in this stage (5). An egg was removed from the incubator and positioned on the stage of a dissecting microscope. Each embryo was exposed either by removing the tape of the all-trans-retinoic acid-treated and sham-operated embryos or making a window in the shell and removing the overlying membranes of the controls. Only live embryos with the right side up and without any sign of bleeding were included in the final analysis. We simultaneously measured blood pressures in the vitelline artery and flow velocities in the dorsal aorta in 47 embryos treated with $1.0 \mu \mathrm{g}$ of all-transretinoic acid and in 15 sham-operated and 21 control embryos. The temperature of the embryo during the measurement was regulated by a thermoelement and was maintained at $37^{\circ} \mathrm{C}$.

Blood pressure was measured in the left vitelline artery with a servo-null system (model 900A, World Precision Instruments, Inc., Sarasota, FL) and a $10-\mu \mathrm{m}$ glass micropipette. This pressure system was tested against a standing water column. A total of 26 measurements were performed. The relationship between the servo-null pressure system and the water column pressure was determined by regression analysis. The method was linear from $-5 \mathrm{~mm} \mathrm{Hg}$ to $40 \mathrm{~mm} \mathrm{Hg}(y=$ $1.14 x+0.25, r^{2}=0.99$, SEM of estimate $=0.12 \mathrm{~mm} \mathrm{Hg}$ ). Zero trans-tip pressure was obtained by immersing the tip of the micropipette in the extraembryonic fluid at the level of the measured site (1).

Mean dorsal aortic blood flow velocities were measured with a $20 \mathrm{MHz}$ directional pulsed Doppler velocity meter (model $545 \mathrm{C}-4$ by Bioengineering, University of Iowa). In a previous study (2), this equipment had been validated to be accurate above $5 \mathrm{~mm} / \mathrm{s}$. The Doppler probe consisting of a $750-\mu \mathrm{m}$ piezoelectric crystal was positioned at a $45^{\circ}$ angle to the dorsal aorta at the level of the sinus venosus as described in earlier reports $(1,2)$.

The internal diameter of the dorsal aorta was measured at the same level with a filar micrometer eyepiece which was calibrated against a $10-\mu \mathrm{m}$ engraved glass standard. The vessel area was calculated from the equation area $=\pi d^{2} / 4$ where $d$ is the aortic diameter (mm).

Hemodynamic parameters. The analog wave forms were sampled at $300 \mathrm{~Hz}$ by a LAB MASTER data acquisition analog-digital board (Axon Instruments Inc., Burlingame, CA) linked to a Commodore PC40 computer. The converter offered 12 bits at an input range of -10 to $10 \mathrm{~V}$. Data were stored in a 51/4-inch 90-megabyte Bernoulli disk cartridge (Iomega Corp., Roy, UT).

Within each embryo a 2-min wave form recording was made. A technically high quality wave form recording of $10 \mathrm{~s}$ was selected for analysis. Each 10 -s recording contained 20 to 40 wave forms.

Peak systolic, diastolic, and mean blood pressures were determined. Vitelline artery $\mathrm{dP} / \mathrm{dt}(\mathrm{mm} \mathrm{Hg} / \mathrm{s})$ was derived from the analog pressure signal by digital differentiation.

Mean dorsal aortic blood flow $\left(\mathrm{mm}^{3} / \mathrm{s}\right)$ was calculated as the product of the mean velocity and the area of the dorsal aorta (2). By measuring the cycle length between pulse waves and converting this into beats per minute, the heart rate was calculated. The peak acceleration $\mathrm{dV} / \mathrm{dt}\left(\mathrm{mm} / \mathrm{s}^{2}\right)$ was derived from the dorsal aortic velocity by means of digital differentiation. Stroke volume $\left(\mathrm{mm}^{3}\right)$ was determined from the quotient of mean dorsal aortic blood flow and heart rate multiplied by 60. Cardiac work $\left(\mathrm{mm}^{3} \cdot \mathrm{mm} \mathrm{Hg}\right)$ is the product of stroke volume and mean arterial pressure. Vascular resistance $[\mathrm{mm} \mathrm{Hg}$ / $\left.\left(\mathrm{mm}^{3} / \mathrm{s}\right)\right]$ is the quotient of mean arterial pressure and mean dorsal aortic blood flow.

Morphologic examination. After the wave form recordings were collected all 83 embryos were removed from the egg and were processed for histologic sectioning in a routine way by fixing in Bouin and embedding in paraffin. Thereafter, the embryos including the hearts were serially sectioned. The sections were $5 \mu \mathrm{m}$ thick and stained with Mayer's hematoxylin/eosin (5).

To exclude growth retardation at $\mathrm{HH}$ stage 34 , the embryo, heart, and extraembryonic vascular bed were weighed in an additional study of 32 embryos. These were subdivided into 17 embryos treated with all-trans-retinoic acid, seven shamoperated embryos, and eight controls. For this purpose the vitelline membrane was stripped away from the yolk, and each tissue was removed and rinsed with chick Ringer's solution. The specimen was placed on Parafilm and gently blotted to remove excess water and weighed on a Mettler balance accurate to $\pm 100 \mu \mathrm{g}$. The ventricles and atria including the great vessels were weighed after the vessels distal to the aorta and pulmonary trunk were trimmed off.

Statistical analysis. From each control embryo an additional wave form recording of 10 heart cycles was selected to analyze the reproducibility of the blood pressure readouts. The reproducibility $(r)$ was defined according to the equation: $r=$ $\sigma_{\mathrm{B}^{2}} /\left(\sigma_{\mathrm{B}^{2}}+\sigma_{\mathrm{W}^{2}}\right)$, in which $\sigma_{\mathrm{B}^{2}}$ represents the between-embryo variance and $\sigma_{\mathrm{W}^{2}}$ the within-embryo variance. These variances were estimated from an analysis of variance. The reproducibility of the flow velocity parameters had been determined to be satisfactory (2).

Finally, the hemodynamic data were correlated with the morphology. The distribution of hemodynamic parameters was non-Gaussian. Therefore, a nonparametric statistical analysis was carried out. The data are presented as characteristics of the frequency distribution of the hemodynamic parameters by medians and ranges (minimum, maximum). Statistical compar- 
ison was done by the Kruskal-Wallis test, whereas the MannWhitney test was used to determine significant differences between control and experimental values. An exact trend test in a $3 \times 2$ cross-table was used for the dorsal aortic area because this parameter had only three ordered levels. The statistical significance level was defined as a $p$ value of less than $1 \%$ ( $p$ $<0.01$ ) because several parameters were tested.

\section{RESULTS}

Morphology. After histologic analysis, the heart malformations showed a spectrum of a rightward shift of the aorta. In 32 out of 47 embryos treated with all-trans-retinoic acid, no septation abnormalities of the heart could be found. The remaining 15 hearts showed a rightward positioned aorta with an additional subaortic ventricular septal defect. Therefore, all 47 embryos treated with all-trans-retinoic acid were subdivided into two major groups, those with a (subaortic) ventricular septal defect $(n=15)$ and those without a ventricular septal defect $(n=32)$. All hearts of the controls $(n=21)$ and 13 hearts of sham-operated embryos were normal. Two hearts of the sham-operated embryos had a subaortic ventricular septal defect although different from the ventricular septal defect encountered in embryos treated with all-trans-retinoic acid. The results of measurements of whole embryo, heart, and extraembryonic vascular bed wet weights are presented in Table 1. There was no significant difference between embryos treated with all-trans-retinoic acid, sham-operated embryos, and control embryos.

Hemodynamics. The characteristics of the frequency distribution of the dorsal aortic wave form parameters of control embryos, sham-operated embryos, and embryos treated with all-trans-retinoic acid can be seen in Figure 1, $A-G$. There was no significant discrepancy in hemodynamics of control and sham-operated embryos. The two sham-operated embryos with a subaortic ventricular septal defect had normal hemodynamic parameters. Hemodynamics of control and sham-operated embryos were compared with all-trans-retinoic acid-treated embryos. Heart rate, peak systolic and mean velocities, peak systolic and mean blood flows, and peak acceleration and

Table 1. Embryo, heart, and extraembryonic vascular bed wet weights of HH stage 34 control and experimental chick embryos, $p>0.01$

\begin{tabular}{lcccc}
\hline & & & \multicolumn{2}{c}{ Retinoic acid treated } \\
\cline { 4 - 5 } & $\begin{array}{c}\text { Control } \\
(n=8)\end{array}$ & $\begin{array}{c}\text { Sham } \\
(n=7)\end{array}$ & $\begin{array}{c}\text { No VSD } \\
(n=10)\end{array}$ & $\begin{array}{c}\text { Subaortic VSD } \\
(n=7)\end{array}$ \\
\hline $\begin{array}{l}\text { Embryo (g) } \\
\text { Minimum }\end{array}$ & 1.189 & 1.214 & 1.024 & 1.135 \\
Median & 1.253 & 1.326 & 1.209 & 1.199 \\
Maximum & 1.336 & 1.388 & 1.432 & 1.481 \\
Heart (g) & & & & \\
Minimum & 0.012 & 0.011 & 0.012 & 0.011 \\
Median & 0.013 & 0.014 & 0.014 & 0.015 \\
Maximum & 0.016 & 0.017 & 0.017 & 0.017 \\
Extraembryonic vascular bed (g) & & & \\
Minimum & 0.975 & 0.927 & 0.935 & 0.630 \\
Median & 1.434 & 1.198 & 1.065 & 0.985 \\
Maximum & 1.963 & 1.364 & 1.466 & 1.352 \\
\hline
\end{tabular}

VSD $=$ ventricular septal defect. stroke volume were reduced in embryos after treatment with all-trans-retinoic acid, i.e. embryos with and without a subaortic ventricular septal defect $(p<0.01)$. Moreover, when the latter two subgroups were compared with each other all parameters derived from the flow velocity wave form recording were significantly reduced $(p<0.01)$ in the presence of a subaortic ventricular septal defect except heart rate and peak acceleration.

An example of dorsal aortic flow velocity and pressure wave forms for a $\mathrm{HH}$ stage 34 control embryo, sham-operated embryo, and an embryo treated with all-trans-retinoic acid that appeared to have a subaortic ventricular septal defect is shown in Figure 2. It is clear from this figure that there is a reduction in peak systolic velocity and peak acceleration in the embryo with a subaortic ventricular septal defect after treatment with all-trans-retinoic acid compared with the control and shamoperated embryo. The vitelline artery pressure shows no significant difference between the three groups of embryos.

A cross-table of the dorsal aortic area can be seen in Table 2. The exact trend test in a $3 \times 2$ cross-table determined that this parameter was reduced in embryos with a subaortic ventricular septal defect after treatment with all-trans-retinoic acid $(p<0.01)$.

The peak systolic and diastolic blood pressures measured in the left vitelline artery of control and sham-operated embryos and embryos treated with all-trans-retinoic acid showed no significant difference (Table 3 ). The $\mathrm{dP} / \mathrm{dt}$ showed a reduction in embryos treated with all-trans-retinoic acid but was not significant. It was not possible to collect satisfactory pressures in all embryos because sometimes the tip of the glass micropipette was clogged up before an adequate pressure could be recorded. The results of the analysis of variance for each of the pressure parameters is shown in Table 4. The correlation coefficient $(r)$ that represents the reproducibility, using the average of 10 cycles as measurement outcome, was above 0.95 .

The vascular resistance and cardiac work are shown in Figure 3, $A$ and $B$. Vascular resistance was elevated and cardiac work reduced in embryos with a subaortic ventricular defect when compared with the sham-operated embryos $(p<0.01)$. Furthermore, in contrast with control embryos, embryos with a subaortic ventricular defect showed a significant decrease in cardiac work $(p<0.01)$. The degree of dextroposition of the aorta in embryos without ventricular septal defect, does not seem to have a significant impact on the hemodynamic parameters measured.

\section{DISCUSSION}

In the present study dorsal aortic flow velocity and vitelline artery pressure wave forms were recorded in $\mathrm{HH}$ stage 34 (d 8 of incubation) embryos treated with all-trans-retinoic acid, sham-operated embryos and control embryos. Hemodynamics of control and sham-operated embryos showed no significant difference. The presence of a ventricular septal defect in 2 out of 15 sham-operated embryos had no effect on hemodynamic outcome. The $13.3 \%$ incidence of this type of ventricular septal defect is in the range of spontaneous occurred of $11.7 \%$ of 

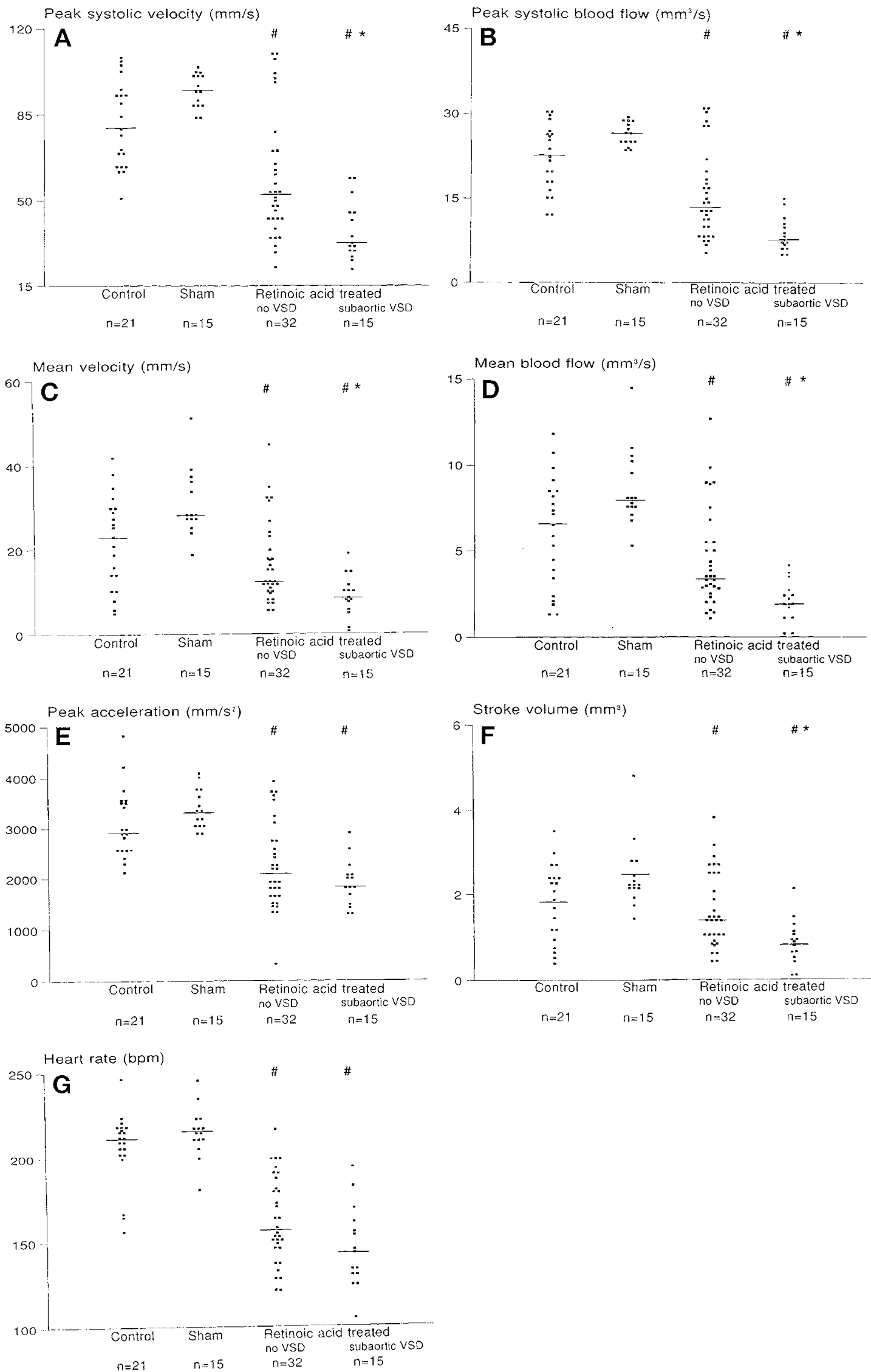

Figure 1. $(A-G)$ The characteristics of the frequency distribution of the dorsal aortic wave form parameters. \#, Significantly different from control and sham operated embryos $(p<0.01)$. ", Significantly different from embryos treated with all-trans-retinoic acid without VSD; $p<0.01)$. VSD $=$ ventricular septal defect 


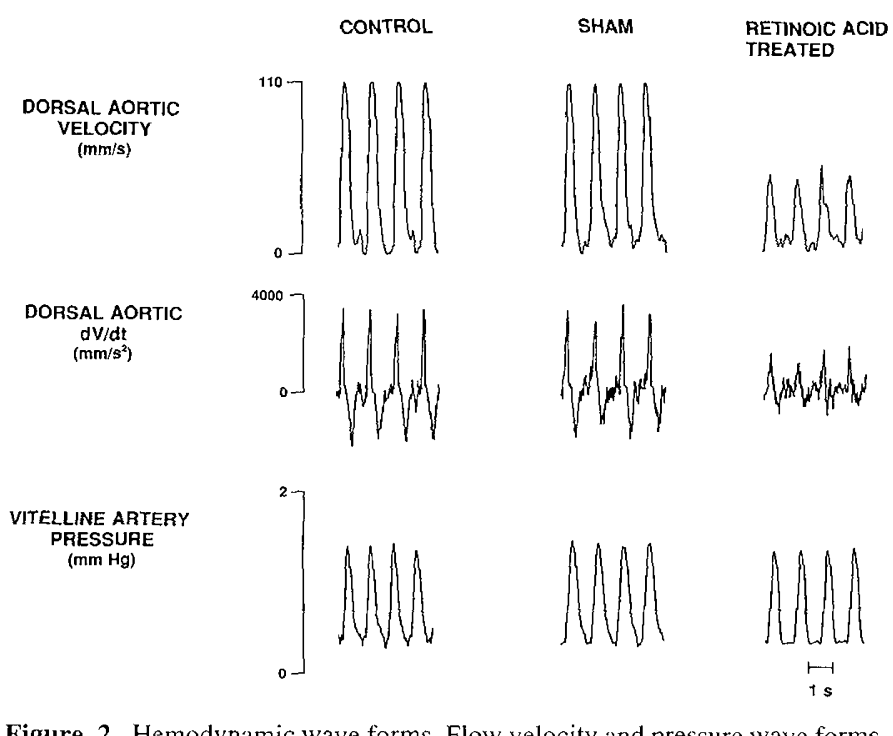

Figure 2. Hemodynamic wave forms. Flow velocity and pressure wave forms of a control embryo, sham embryo and a retinoic acid treated embryo that appeared to have a subaortic ventricular septal defect.

Table 2. A cross-table of dorsal aortic area by control and experimental HH stage 34 chick embryos

\begin{tabular}{|c|c|c|c|c|}
\hline \multirow[b]{2}{*}{$\begin{array}{l}\text { Dorsal aortic } \\
\text { area }\left(\mathrm{mm}^{2}\right)\end{array}$} & \multirow[b]{2}{*}{$\begin{array}{l}\text { Control } \\
(n=21)\end{array}$} & \multirow[b]{2}{*}{$\begin{array}{c}\text { Sham } \\
(n=15)\end{array}$} & \multicolumn{2}{|c|}{ Retinoic acid treated } \\
\hline & & & $\begin{array}{l}\text { No VSD } \\
(n=32)\end{array}$ & $\begin{array}{c}\text { Subaortic VSD } \\
(n=15)(p<0.01)\end{array}$ \\
\hline 0.19 & 1 & 0 & 3 & 4 \\
\hline 0.23 & 4 & 1 & 11 & 10 \\
\hline 0.28 & 16 & 14 & 18 & 1 \\
\hline
\end{tabular}

Table 3. Characteristics of the frequency distribution of the vitelline arterial pressure parameters of control and experimental HH stage 34 chick embryos, $p>0.01$

\begin{tabular}{|c|c|c|c|c|}
\hline & \multirow[b]{2}{*}{$\begin{array}{c}\text { Control } \\
(n=11)\end{array}$} & \multirow[b]{2}{*}{$\begin{array}{c}\text { Sham } \\
(n=11)\end{array}$} & \multicolumn{2}{|c|}{ Retinoic acid treated } \\
\hline & & & $\begin{array}{l}\text { No VSD } \\
(n=27)\end{array}$ & $\begin{array}{l}\text { Subaortic VSD } \\
\quad(n=10)\end{array}$ \\
\hline \multicolumn{5}{|c|}{ Peak systolic pressure $(\mathrm{mmHg}$ ) } \\
\hline Minimum & 0.8 & 0.7 & 0.5 & 0.9 \\
\hline Median & 2.9 & 1.8 & 2.2 & 1.7 \\
\hline Maximum & 4.2 & 4.1 & 6.4 & 2.7 \\
\hline \multicolumn{5}{|c|}{ Diastolic pressure $(\mathrm{mmHg})$} \\
\hline Minimum & 0.05 & 0.06 & 0.01 & 0.05 \\
\hline Median & 0.6 & 0.6 & 0.5 & 0.3 \\
\hline Maximum & 1.9 & 1.6 & 2.7 & 0.9 \\
\hline \multicolumn{5}{|c|}{ Mean pressure (mmHg) } \\
\hline Minimum & 0.3 & 0.4 & 0.03 & 0.2 \\
\hline Median & 1.1 & 0.9 & 1.1 & 0.8 \\
\hline Maximum & 2.9 & 2.1 & 3.2 & 1.4 \\
\hline \multicolumn{5}{|c|}{$\mathrm{dP} / \mathrm{dt} \max (\mathrm{mm} \mathrm{Hg} / \mathrm{s})$} \\
\hline Minimum & 20.5 & 20.2 & 5.7 & 9.8 \\
\hline Median & 33.8 & 34.2 & 30.4 & 25.3 \\
\hline Maximum & 52.4 & 50.3 & 96.3 & 34.1 \\
\hline
\end{tabular}

VSD $=$ ventricular septal defect.

cardiac malformations seen in the chick embryo, and the majority closes before hatching (7). It is described that DMSO by itself can interfere with normal development by producing defects of head and limbs (8). As solvent it can produce very important changes in the teratogenic effectiveness of biologically active compounds. This could explain the $31.9 \%$ inci-
Table 4. Results of analysis of variance

\begin{tabular}{cccc}
\hline Pressure (mmHg) & $\sigma_{\mathrm{w}}{ }^{2 *}$ & $\sigma_{\mathrm{B}}{ }^{2} \dagger$ & $r \neq$ \\
\hline Peak systolic & 0.02 & 7.38 & 1.00 \\
Diastolic & 0.10 & 3.57 & 0.97 \\
Mean & 0.01 & 4.77 & 1.00 \\
\hline
\end{tabular}

* Variance within embryos.

$\dagger$ Variance between embryos.

$\ddagger$ Reproducibility (correlation coefficient).

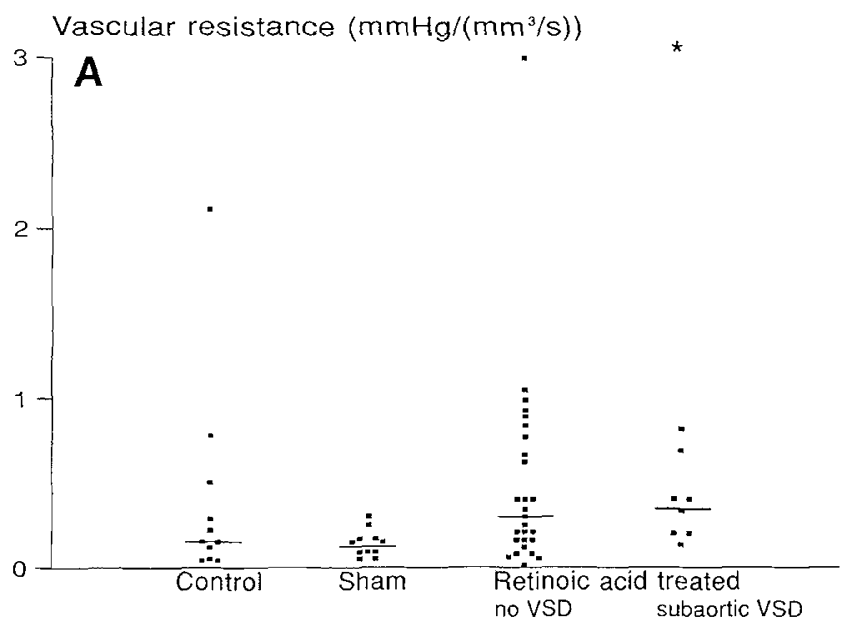

Cardiac work $\left(\mathrm{mm}^{3} \times \mathrm{mmHg}\right)$

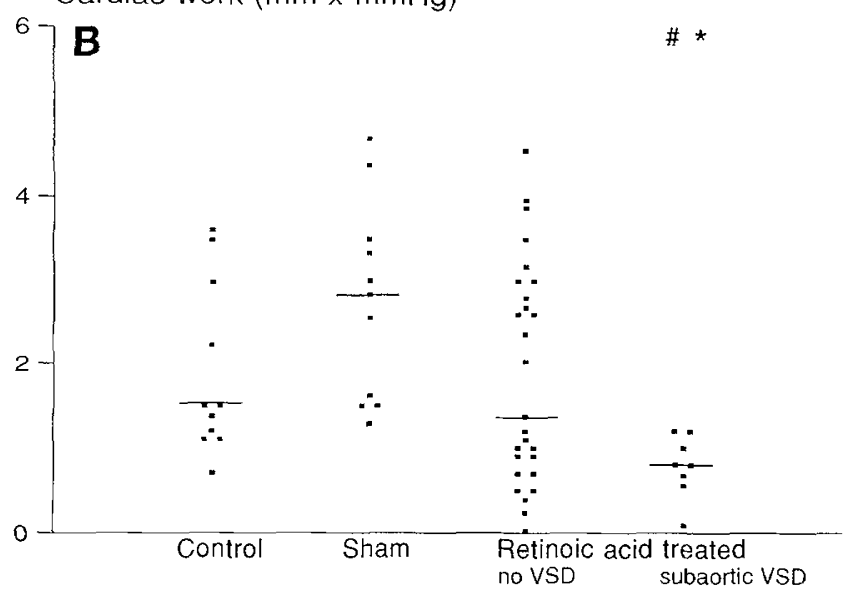

Figure 3. $(A$ and $B$ ) The characteristics of the frequency distribution of the vascular resistance and cardiac work. \#, Significantly different from control embryos $(p<0.01)$. ${ }^{*}$, Significantly different from sham operated embryos $(p$ $<0.01)$. VSD $=$ ventricular septal defect.

dence and severity of the cardiac malformations seen after treatment with all-trans-retinoic acid.

Hemodynamics of retinoic acid-treated embryos and control and sham-operated embryos were compared with each other. A significant decrease in heart rate, peak systolic and mean velocities, peak systolic and mean blood flows, and peak acceleration and stroke volume was observed in embryos treated with all-trans-retinoic acid. A comparison was also carried out between the two subgroups of embryos treated with all-trans-retinoic acid. All parameters derived from the flow velocity wave form recording were significantly reduced in the presence of a subaortic ventricular septal defect except heart rate and peak acceleration. Moreover, the dorsal aortic area, that was determined from the vessel diameter, was reduced in 
these embryos. Pressure readings were not essentially different between control and sham-operated embryos and all embryos treated with all-trans-retinoic acid. Therefore, the increase in vascular resistance and decrease in cardiac work in embryos with a subaortic ventricular defect can only be explained by the observed decrease in volume flow. The latter finding could not be the result of a possible growth retardation because the measurements of whole embryo, heart, and extraembryonic vascular wet weights showed no significant differences between retinoic acid treated embryos, sham-operated embryos, and control embryos.

The hemodynamic changes seen in retinoic acid treated embryos, in particular the reduced peak acceleration and stroke volume, suggest a decrease in cardiac contraction force. The peak acceleration was derived from the dorsal aortic velocity and indicates the contraction potential of the heart. Stroke volume was determined from mean dorsal aortic blood flow and heart rate. The decrease in heart rate may be caused by an immature impulse formation in the conduction system due to a delay in the maturation process of the heart. In a previous report we described the physiologic increase of heart rate between stage 20 to stage 35 (2). Comparison between the two subgroups of retinoic acid treated embryos revealed in embryos with a subaortic ventricular septal defect a significant reduction of all wave form parameters, except heart rate and peak acceleration. The latter suggests no significant difference in cardiac contraction force between the two subgroups. The abnormal morphology in combination with the decrease in cardiac contraction force could account for the impaired volume flow and could lead to the calculated reduction in vessel area in these embryos.

We propose that the hemodynamic changes presented in this study are mainly due to myocardial dysfunction and to a lesser extent to abnormal cardiac morphology in embryos that were treated with all-trans-retinoic acid. A decrease in cardiac contraction force was found in these embryos regardless the presence of a ventricular septal defect. Although the mechanism is unclear, we postulate that all-trans-retinoic acid may have an indirect and a direct effect on the myocardium.

The indirect effect may result from an impaired parasympathetic innervation through a disturbance of the migration of cells from the neural crest. It is described that neural crest cells contribute to the cardiac ganglia $(9,10)$. Parasympathetic innervation of the heart via the cardiac ganglia could be impaired after treatment with retinoic acid. The effect of alltrans-retinoic acid on the neural crest may be through cytotoxicity (11) or result from alterations in region-specific signals necessary for homing of neural crest cells or for their differentiation (12). Furthermore, in vitro mesenchymal cell migration is inhibited by retinoids $(13,14)$. Impaired parasympathetic innervation could lead to an alteration of the tonus of the cardiac myocytes.

A direct effect cannot be excluded. Evidence exists that 13-cis-retinoic acid and all-trans-retinoic acid have multiple effects on growth and differentiation of cardiac myocytes, including an inhibition of cell proliferation, development of heart contractions, and delay in $\alpha$-actin synthesis (15). Retinoic acid may have direct effects on the myocytes by disruption of gap junctional communication (16) that could be mediated through retinoid-binding proteins $(17,18)$ and the nuclear receptors (19). Pexieder et al. (20) showed that all-transretinoic acid can modify cardiac contractility. In rat fetuses treated during early pregnancy with all-trans-retinoic acid, a higher sensitivity toward extracellular calcium ion variations was found. This could indicate a larger permeability (immaturity) of the sarcolemma and/or delayed development of the sarcoplasmic reticulum (20). Furthermore, they reported that all-trans-retinoic acid significantly decreased the total amount of protein in morphologically normal mouse hearts and hearts that showed a double outlet right ventricle. In these morphologically normal and abnormal hearts, the concentration of sarcoplasmic proteins was significantly increased and that of contractile proteins decreased. Results of our study coincide with their data that, in embryos treated with all-trans-retinoic acid complementary with structural changes of the myocardium, the function of the embryonic heart is also affected. Both direct and indirect effects on the myocardium could generate myocardial dysfunction in various ways and lead to the same result i.e., a decrease in cardiac contraction force.

In conclusion we put forward that the hemodynamic changes observed in embryos after treatment with all-trans-retinoic acid are the result of a decrease in cardiac contraction force. Our results suggest there was no significant difference in contraction force between the two subgroups, embryos with and without ventricular septal defect, of retinoic acid-treated embryos. The presence of a subaortic ventricular septal defect in combination with the myocardial dysfunction could account for impaired volume flow and could lead to the observed diminished dorsal aortic diameter in these embryos.

Regulation of cardiac growth and function involves the orchestration of hemodynamic and cellular events. Further longitudinal studies will be conducted to evaluate the degree of altered myocardial contractility. These studies concern myocardial innervation and immunohistochemistry of the contractile apparatus.

\section{REFERENCES}

1. Hu N, Clark EB 1989 Hemodynamics of stage 12 to stage 29 chick embryo. Circ Res 65:1665-1670

2. Broekhuizen MLA, Mast F, Struijk PC, Van der Bie W, Mulder PGH, Gittenberger-de Groot AC, Wladimiroff JW 1993 Hemodynamic parameters of stage 20 to stage 35 chick embryo. Pediatr Res 34:44-46

3. Lammer EJ, Chen DT, Hoar RM, Angish ND, Benke PJ, Braun JT, Curry CJ, Fernhoff PM, Grix AW, Lott IT, Richard JM, Sun SC 1985 Retinoic acid embryopathy. N Engl J Med 313:837-841

4. Pexieder T, Pfizenmaier Rousseil M, Prados-Frutos JC 1992 Prenatal pathogenesis of the transposition of great arteries. In: Vogel M, Bühlmeyer K (eds) Transposition of the Great Arteries 25 Years after Rashkind Balloon Septostomy. Steinkopff Verlag, Darmstadt, pp 11-27

5. Broekhuizen MLA, Wladimiroff JW, Tibboel D, Poelmann RE, Wenink ACG, Gittenberger-de Groot AC 1992 Induction of cardiac anomalies with all-trans-retinoic acid in the chick embryo. Cardiol Young 2:311-317

6. Hamburger V, Hamilton HL 1951 A series of normal stages in the development of the chick embryo. J Morphol 88:49-92

7. Kuhlmann RS, Kolesari GL 1984 The spontaneous occurrence of aortic arch and cardiac malformations in the white Leghorn chick embryo (Gallus domesticus). Teratology 30:55-59

8. Landauer W, Salam N 1972 Aspects of dimethyl sulphoxide as solvent for teratogens. Dev Biol 28:35-46

9. Kirby ML, Stewart D 1983 Neural crest origin of cardiac ganglion cells in the chick embryo: Identification and extirpation. Dev Biol 97:433-443

10. Kirby ML 1993 Cellular and molecular contributions of the cardiac neural crest to cardiovascular development. Trends Cardiovasc Med 3:18-23 
11. Jelinek R, Kistler A 1981 Effect of retinoic acid upon the chick embryonic morphogenetic systems. The embryotoxicity range. Teratology 23:191-195

12. Hart RC, McCue PA, Ragland WL, Winn KJ, Unger ER 1990 Avian model for 13 cis retinoic acid embryopathy: demonstration of neural crest related defects. Teratology $41: 463-472$

13. Thorogood P, Smith L, Nicol A, McGinty R, Garrod D 1982 Effects of vitamin A on the behavior of migratory neural crest cells in vitro. J Cell Sci 57:331-350

14. Smith-Thomas L, Lott I, Bronner-Fraser M 1987 Effects of isotretinoin on the hehavior of neural crest cells in vitro. Dev Biol 123:276-280

15. Wiens DJ, Mann TK, Fedderson DE, Rathmell WK, Franck BH 1992 Early heart devclopment in the chick embryo: Effects of isotretinoin on cell proliferation, $\alpha$-actin synthesis, and devclopment of contractions. Differentiation 51:105-112

16. Mehta P, Bertram J, Locwenstein W 1989 The actions of retinoids on cellular growth correlate with their actions on gap junctional communication. J Cell Biol 108:1053-1065
17. Maden M, Ong DE, Summerbell D, Chytil F 1989 The role of retinoid- binding proteins in the generation of pattern in the developing limb, the regenerating limb and the nervous system. Development 107(suppl):109-119

18. Maden M, Hunt P, Erikson U, Kuroiwa A, Krumlauf R, Summerbell D 1991 Retinoic acid-binding protein, thombomeres and the ncural crest. Development 111:35-44

19. Ruberte E, Dollé P, Chambon P, Morriss-Kay G 1991 Retinoic acid receptors and cellular retinoid binding proteins. II. Their differential pattern of transcription during carly morphogenesis in mousc embryos. Development 111:45--60

20. Pexieder T, Blanc O, Pelouch V, Oštádalová I, Milerová M, Ošť́dal B 1995 Late fetal devclopment of retinoic acid induced transposition of great arteries- morphology, physiology and biochemistry. In: Markwald RR, Clark EB, Takao A (eds) Developmental Mechanisms of Hearl Disease. Futura Publishing Company, Armark, NY, pp 297-307 